\title{
Atributos Estratégicos nas Compras de Estabelecimentos de Hospedagens: estudo das pousadas de Ouro Preto e Tiradentes no roteiro turístico "Estrada Real"
}

\section{Strategic Purchasing Attributes of Lodging Establishments: study of the hostels in Ouro Preto and Tiradentes in the "Royal Road" tourist route}

\author{
Ricardo S. Martins ${ }^{1}$ \\ Débora S. Lobo ${ }^{2}$ \\ Letícia Labegalini $^{3}$ \\ Alexandre de Pádua Carrieri ${ }^{4}$
}

\section{Resumo}

O objetivo geral da presente pesquisa foi identificar necessidades e expectativas de pousadas nas cidades históricas de Ouro Preto e Tiradentes na Estrada Real (MG), em termos de estratégia para a logística de suprimentos. No caso dos serviços relacionados ao turismo, o uso estratégico da logística permite alcançar diferenciais competitivos tanto no aspecto custos quanto na qualidade do atendimento. Através de pesquisa de campo, foram aplicados cartões aos empresários e gerentes dos estabelecimentos de pousadas nas regiões de Ouro Preto e Tiradentes, com base na técnica estatística multivariada Preferência Declarada. Os cartões constavam de alguns atributos que mostrariam a configuração preferida dos serviços de suprimentos. Os atributos investigados foram: prazo de atendimento, número de fornecedores, tamanho do lote, operações de suprimentos e forma de pedido. Os resultados indicaram que uma estratégia de forte impacto para as pousadas das regiões pesquisadas deveria contemplar política de redução da base de fornecedores.

Palavras-chave: logística de suprimentos; logística para serviços; turismo; Minas Gerais.

\footnotetext{
${ }^{1}$ Professor Dr. do Departamento de Administração e Centro de Pós-Graduação e Pesquisa em Administração (CEPEAD),Universidade Federal de Minas Gerais (UFMG). Pesquisador do Núcleo Interdisciplinar de Pesquisa e Extensão em Logística (NIPE-LOG/UFMG). Email: martins@cepead.face.ufmg.br.

2 Professora Adjunta da Unioeste/Campus de Toledo e membro do Translog - Grupo de Pesquisas em Transportes e Logística Agroindustrial. Email: dslobo@uol.com.br.

${ }^{3}$ Administradora, Mestre em Administração pela Fundação Getúlio Vargas - São Paulo. Pesquisadora do Núcleo Interdisciplinar de Pesquisa e Extensão em Logística (NIPE-LOG/UFMG). Email: lelabega@hotmail.com.

${ }^{4}$ Professor Dr. do Departamento de Administração e Centro de Pós-Graduação e Pesquisa em Administração (CEPEAD)/Universidade Federal de Minas Gerais (UFMG). Pesquisador do Núcleo de Estudos Organizacionais e Simbolismo - NEOS. Email: alexandr@cepead.face.ufmg.br .
} 


\begin{abstract}
The general objective of this article was to identify the needs and expectations of the service suppliers connected to tourism along the historic route known as the "Royal Highway" (in the State of Minas Gerais, Brazil), in terms of the desired strategy for the logistics of supply for this type of tourism. By means of exploratory empirical research, a survey of the data was carried out in the field by presenting cards that clearly stated preferences regarding suppliers to owners and managers of inns in the regions of the cities of Ouro Preto and Tiradentes. The features investigated were: Speed of Service, Number of Suppliers, Size of Lots, Supply Operations and Method of Ordering. The article concludes that, in order for a strategy to have strong impact on this economic activity in the regions where this research was carried out, it should consider a policy of reducing the supplier basis.
\end{abstract}

Keywords: suppliers logistics, services logistics, tourism management, Minas Gerais.

\title{
1. Introdução
}

Em geral, de acordo com Quan e Wang (2004), há duas abordagens aos estudos do turismo: a abordagem da ciência social e da gestão. A primeira é caracterizada pela experiência do turista e é entendida como sendo experiências estritamente diferenciadas daquelas experimentadas no seu cotidiano (Mossberg 2007). A outra perspectiva, a da literatura da gestão do turismo, enquanto atividade econômica, trata os turistas como consumidores que estão envolvidos em relações comerciais. Tais relações (transações) cobrem todos os tipos de serviços, não importando sua natureza (Mossberg 2007).

Os gerentes dos serviços têm como principais tarefas formatar uma combinação que seja percebida como valor para estes consumidores, motivando-os a comprar e satisfazer, desta forma, suas necessidades e expectativas de consumo. (Kotler et al. 1999). Na gestão do turismo, num restaurante, o produto consiste na combinação da comida e bebida, conjugada com outros aspectos mesmo intangíveis, tais como os componentes do ambiente - requinte, aconchego, plantas e música (Hansen et al. 2005).

A logística compreende boa parte dos serviços que tornam este valor percebido pelos consumidores. O uso combinado de suas atividades - transporte, estoque, informação tornam possível a definição de estratégias que viabilizam processos diferenciados de 
suprimentos e produção de serviços que contribuem para que os produtos consumidos e os componentes do ambiente únicos e diferenciados, reconhecidos pelos consumidores pela diferenciação da qualidade em si, da capacidade de atendimento dos estabelecimentos e/ou pelos preços pagos. Ou seja, os processos logísticos apresentam-se como oportunidades de diferenciação dos negócios, oportunidades estas entendidas como estratégias capacitadas a gerar vantagens competitivas sustentáveis.

Os suprimentos, relevantes ao presente estudo, são responsáveis pelas atividades relacionadas à obtenção de materiais (produtos acabados, peças, componentes e matéria-prima) e contratação de serviços de fornecedores externos. Inclui tradicionalmente atividades de transporte, manutenção de estoques, processamento de pedidos, compras, embalagem, armazenagem, manuseio de materiais e manutenção de informações relativas. Poirier e Reiter (1997) complementam que é de responsabilidade desse subsistema realizar a execução do planejamento de recursos, localização de fontes de suprimento, negociação, disposição de pedidos, recebimento e inspeção, garantia de qualidade e quantidade de fornecimento, tendo como principal objetivo o apoio à produção.

Neste caso, destaca-se a atividade de Compras do subsistema Suprimentos, que consiste em: análise de produtos, pesquisando os requisitos necessários para produtos e serviços; pesquisa de mercado, determinando as características de mercado para uma determinada aquisição; rastreamento e acompanhamento de pedidos; determinação de necessidades e requisitos dos clientes internos; transmissão aos fornecedores das previsões a respeito de futuras necessidades; transmissão de ordens de compras atuais aos fornecedores; medição de desempenho dos fornecedores; gestão da qualidade dos fornecedores, garantindo que seus produtos e serviços atendam a requisitos especificados; gestão dos contratos e negociações, desenvolvendo os termos corretos; gestão do suprimento e da distribuição, assegurando entregas corretas e dentro do prazo; e análise de custo e de preço, analisando inclusive tendências futuras (Monczka et al, 2002).

Já dentro de uma perspectiva estratégica, a gestão de compras - strategic sourcing - lida com um escopo maior do que a perspectiva operacional. Para Monczka et al (2002), é um processo multifuncional, não se restringindo aos membros diretamente ligados ao departamento formal 
de compras. O foco da gestão estratégica de compras envolve a gestão, o desenvolvimento e a integração com a capacidade dos fornecedores, a fim de se obter uma vantagem competitiva, ligada a efeitos de redução de custos, desenvolvimento de tecnologia, melhoramento da qualidade, redução do tempo de ciclo e melhoramento da capacidade de entrega, a fim de atender as necessidades dos clientes.

No caso do turismo, o uso estratégico da logística permite alcançar diferenciais competitivos tanto no aspecto custos dos serviços quanto na qualidade do atendimento. Há potenciais ganhos em competitividade através da redução dos preços dos serviços, viabilizada pela redução de estoques e pelas formas de obtenção dos materiais (neste caso citam-se, dentre outros, os de gêneros alimentícios, e materiais de cama, mesa e banho) e custos de transporte.

A qualidade no atendimento pode ser melhorada à medida que viabiliza aumentos na disponibilidade e na variedade dos materiais, o que reflete, por exemplo, no atendimento pleno do pedido via cardápio; na minimização de perda de faturamento por ociosidade de aposentos por eventuais falta de toalhas e lençóis; bem como na insatisfação do cliente por interdições temporárias em diferenciais oferecidos por falta de materiais e equipamentos, tal como falta de material de limpeza de piscinas.

Portanto, o objetivo geral da presente pesquisa é identificar necessidades e expectativas dos prestadores de serviço de hospedagem, especificamente pousadas, na Estrada Real (MG), em termos de estratégia desejável de suprimentos desta opção de turismo em consolidação.

$\mathrm{Na}$ sequência, apresenta-se o contexto histórico do desenvolvimento do roteiro turístico Estrada Real, seguido da metodologia utilizada na pesquisa, os resultados obtidos e as conclusões.

\section{O Roteiro Turístico "Estrada Real”: um contexto histórico-geográfico}

A Estrada Real, tal como é hoje conhecida, mantém uma nítida relação com a história do Brasil e, mais especificamente, com a do estado de Minas Gerais. Nos séculos XVII e XVIII, foram abertos no território brasileiro três caminhos principais, que ligavam os centros de 
exploração de pedras preciosas das Minas Gerais, Ouro Preto e Diamantina, aos portos de escoamento dessas mercadorias - Rio de Janeiro e Paraty - passando também por São Paulo. Essas vias de acesso, de natureza oficial e pertencentes à Coroa Portuguesa, foram então designadas "Estrada Real”, e representavam a única via autorizada para chegar à região das reservas de pedras preciosas no interior do Brasil. Os caminhos especificados acima foram denominados "Caminho Velho", "Caminho Novo" e "Caminho dos Diamantes", e passaram a ser designados "Estrada Real" a partir de 1718, quando se estipulou que toda a mercadoria transportada deveria passar pelos Registros espalhados pelos caminhos (Costa et al,. 2002).

Para a compreensão do fenômeno Estrada Real na história de Minas Gerais é preciso considerar o sistema de tributação de mercadorias no Brasil colonial. O nome Estrada Real surgiu como uma alusão à Fazenda Real, órgão que, na época do surgimento da Estrada, era responsável pela cobrança das taxas de tudo que entrava e saía das Capitanias, e pela cobrança do Quinto.

Os estudos a respeito do desbravamento do território brasileiro indicam que a origem da Estrada Real ocorreu a partir das bandeiras ou entradas. Pode-se chamar de bandeiras ou entradas as expedições realizadas, principalmente por paulistas, que adentravam o interior do Brasil à captura de índios e, mais tarde, à busca de metais preciosos. Devido à necessidade de se encontrar novas fontes de riqueza na colônia, a Coroa Portuguesa passou a desejar que as entradas passassem a ter como principal meta a busca por riquezas no território brasileiro, principalmente a extração de pedras preciosas - ouro, prata e diamante. Assim, a Coroa concedia as chamadas Cartas Régias aos chefes paulistas, a fim de estimular essa busca por minerais. As cartas prometiam prêmios e honorários aos descobridores das reservas de metais preciosos no interior do Brasil.

Desde o início dos anos 2000, iniciou-se um processo de transformação da Estrada Real dos séculos XVII e XVIII em um importante produto turístico para o Brasil e o seu consequente reconhecimento como patrimônio histórico. São mais de $1.400 \mathrm{~km}$ de extensão em um eixo traçado para representar as Estradas Reais da época. Porém, cabe ressaltar que os caminhos que hoje foram delimitados não correspondem exatamente à estrada da época, a qual ultrapassa esses limites com as suas várias vertentes. 
Estes caminhos históricos inspiraram uma série de projetos para a recuperação de seu patrimônio cultural e para a exploração econômica, principalmente através do turismo na região. Tal projeto Instituto Estrada Real (IER), foi criado pela Federação das Indústrias de Minas Gerais, em outubro de 1999, com o objetivo de induzir e fomentar o produto turístico Estrada Real.

O IER trabalha em conjunto com a Secretaria de Turismo do Estado de Minas Gerais (SETUR/MG), as prefeituras das cidades incluídas no trajeto da Estrada Real (ER) e com o Ministério do Turismo. Seu principal objetivo é desenvolver o turismo, dando apoio aos municípios, através da realização de projetos, palestras e seminários específicos para cada região, apresentando a Estrada Real para as comunidades.

\section{Metodologia}

\subsection{Caracterização da pesquisa}

Este artigo caracteriza-se como uma pesquisa empírica, de caráter exploratório, que procurou investigar evidências dos estabelecimentos de hospedagem das cidades de Ouro Preto e Tiradentes, na Estrada Real, quanto às formas mais adequadas de suprimentos de materiais alimentos, cama, mesa e banho. Segundo Malhotra (2001), a pesquisa exploratória é adequada em áreas de poucos conhecimentos acumulados, enquanto a compreensão dos fenômenos ainda não é suficiente ou mesmo inexistente. O caráter empírico da pesquisa está apoiado em levantamento de dados em campo por aplicação de cartões de preferência declarada aos empresários e gerentes dos estabelecimentos.

A unidade de análise de pesquisa refere-se às empresas prestadoras de serviço de hospedagem (pousadas) nas regiões de Ouro Preto e Tiradentes, trechos dos mais consolidados em turismo da Estrada Real, sendo as unidades de observação, empresários e gerentes envolvidos no processo de planejamento e decisão das atividades logísticas dos estabelecimentos.

A coleta de dados ocorreu através de um processo de amostragem do tipo não-probabilístico, por tipicidade, que implica, objetivamente, buscar um estabelecimento com volume 
consistente de oferta de serviços, isto é, serviço não sazonal e com no mínimo 10 apartamentos.

Foram usados recursos estatísticos para a análise das respostas pelo algoritmo desenvolvido por Souza (1999).

\subsection{Estratégias de desenvolvimento metodológico: conhecendo as preferências dos gerentes dos estabelecimentos de turismo}

Análises de mercado apóiam-se em alguns conceitos de comportamento humano na explicação das preferências manifestadas pelos agentes, tanto pessoas quanto organizações, quando esses tentam maximizar sua satisfação. Para Byrns (1996), este comportamento também é vital para tomar decisões de negócios, na tentativa de maximizar a utilização dos recursos empregados no sistema organizacional.

O tratamento estatístico para conhecimento destas preferências pode ser feito através de técnicas estatísticas multivariadas. Dentre elas, Análise Conjunta, de Preferência Revelada e de Preferência Declarada, esta última foi selecionada pela adequação aos propósitos do estudo. Para o desenvolvimento deste trabalho, esta técnica apresenta-se mais adequada que as demais. Isto porque lida essencialmente com situações hipotéticas ou situações nas quais as preferências ou escolhas não podem ser diretamente observadas. Segundo Almeida e Gonçalves (2001), este conjunto de opções pode ser hipotético, mas deve ser viável se efetivada, permitindo aos entrevistados imaginá-las com facilidade.

Segundo Ortúzar (1998), a Preferência Declarada consiste num conjunto de metodologias que se baseiam no juízo declarado por indivíduos acerca de situações hipotéticas que lhe são apresentadas. A Preferência Declarada utiliza técnicas de planejamento de experimentos para elaborar alternativas hipotéticas a serem apresentadas aos respondentes. Permite, então, analisando situações não necessariamente existentes, identificar as características relevantes para os usuários no serviço estudado.

A técnica de Preferência Declarada foi aplicada originalmente em problemas das ciências administrativas na década de 70 na área de marketing. Segundo Louviere et al. (2000), a técnica de Preferência Declarada está sendo largamente utilizada, tanto no setor industrial 
quanto no comercial, e é geralmente, aplicada para:

a) testar a aceitação de novos produtos ou serviços, ou realizar modificações nos atuais;

b) desagregar dados de mercado obtidos via Preferência Revelada;

c) avaliar fatores subjetivos influentes à tomada de decisão.

Através da técnica de Preferência Declarada, é possível identificar a importância relativa de cada atributo. Como diagnóstico isto possibilita uma posterior configuração do serviço mais próxima dos anseios dos agentes.

O problema mais aparente sobre o uso da técnica de Preferência Declarada consiste em questionar se as respostas dos entrevistados sobre suas preferências permanecerão as mesmas quando as diversas situações hipotéticas que lhe forem apresentadas se tornarem reais. $\mathrm{Na}$ década de 80 , esta relação melhorou consideravelmente e recentemente os resultados dos experimentos do uso destas técnicas vêm apresentando aderência satisfatória com a realidade, devido principalmente a um melhor projeto no levantamento dos dados e ao maior rigor no seu tratamento.

\subsubsection{Levantamento das preferências}

Para Jones (1991), algumas etapas devem ser seguidas para se realizar estudos utilizando-se da técnica de Preferência Declarada, quais sejam: a seleção da amostra; definição da forma e a complexidade da técnica; estabelecimento da medida de escolha; o método de entrevistas; e a análise dos dados.

\subsubsection{Amostra}

Formam a amostra os estabelecimentos nas regiões de Ouro Preto e Tiradentes, selecionadas pelo nível de consolidação das atividades de turismo e de identidade com o projeto Estrada Real. No total, foram 130 entrevistas, sendo 70 ocorridas Tiradentes e 60 em de Ouro Preto.

\subsubsection{Instrumento de coleta de dados}

Antes da execução, uma pesquisa prévia junto a uma parcela da amostra associada à 
experiência dos pesquisadores definiu os atributos do serviço que foram estudados e analisados no experimento, bem como os níveis de cada um destes atributos. Esta pesquisa ocorreu no mês de maio de 2007 com visita in loco. Os atributos selecionados, e respectivos níveis, são apresentados na Tabela 1.

$\mathrm{Na}$ etapa de elaboração do experimento, faz-se ainda necessário determinar a forma de apresentação das alternativas aos entrevistados. Um método muito utilizado, devido à facilidade de elaboração e ao custo não muito elevado, é apresentar as alternativas em forma de cartões de escolha contendo os atributos e níveis em forma de figuras auto-explicativas. A confecção destes cartões requer bastante atenção, pois estes devem conter informações claras, precisas e de fácil compreensão para os entrevistados. Atribui-se o código 1 para os formato do atributo manifestado mais desejado em pré-pesquisa realizada; caso contrário, o código é 0. Os cartões e respectivas figuras ilustrativas dos atributos que foram utilizadas são apresentados na Figura 1.

A complexidade do experimento cresce conforme aumenta o número de atributos e seus níveis. Jones (1991) sugere que o número máximo a ser utilizado nos níveis não pode passar de três, em virtude de que a complexidade do experimento aumenta e prejudica a análise por parte do entrevistado. Neste sentido, Bateman (2002) salienta que quando os números de alternativas forem passíveis de prejudicar a análise por parte dos entrevistados, recomenda-se ainda, utilizar o fatorial fracionado, isto é, reduzir o número de alternativas dispostas à frente do entrevistado.

Tabela 1 - Os atributos selecionados, e respectivos níveis e códigos numéricos

\begin{tabular}{|c|l|c|}
\hline \multirow{2}{*}{ Atributo } & \multicolumn{1}{|c|}{ Níveis } & $\begin{array}{c}\text { Código } \\
\text { Numérico }\end{array}$ \\
\hline \multirow{3}{*}{ Prazo } & $\begin{array}{l}\text { Até 24 horas: ciclos de pedido (período entre a efetivação do pedido e a } \\
\text { entrada do suprimento no estabelecimento) mais curtos implicariam reações } \\
\text { mais rápidas frente a surpresas proporcionadas pela demanda. }\end{array}$ & 1 \\
\cline { 2 - 4 } & $\begin{array}{l}\text { Mais de 24 horas: ciclos de pedido mais longos são indesejáveis para o } \\
\text { empresário, pois o obrigam a fazer determinado planejamento nem sempre } \\
\text { bem apoiado pela demanda, que é sazonal, ocasionalmente gerando } \\
\text { estoques. }\end{array}$ & 0 \\
\hline
\end{tabular}




\begin{tabular}{|c|c|c|}
\hline \multirow{2}{*}{ Fornecedores } & $\begin{array}{l}\text { Um ou poucos: um ou alguns poucos fornecedores oferecem um mix } \\
\text { variado de produtos que diminui sensivelmente a necessidade de contatos } \\
\text { para obter todo o suprimento necessário. }\end{array}$ & 1 \\
\hline & $\begin{array}{l}\text { Vários: vários fornecedores têm que ser contatados para serem feitos os } \\
\text { pedidos, como por exemplo, } 1 \text { para carne de boi, outro para carne de porco, } \\
\text { outro para truta, outro para produtos de limpeza,... }\end{array}$ & 0 \\
\hline \multirow[b]{2}{*}{ Lote } & $\begin{array}{l}\text { Pequeno: o lote pequeno se refere a quantidades adequadas para o } \\
\text { atendimento dos estabelecimentos em períodos curtos, sendo esta uma } \\
\text { alternativa importante para a tão sonhada minimização dos custos. }\end{array}$ & 1 \\
\hline & $\begin{array}{l}\text { Grande: como as compras são feitas individualmente por estabelecimento, } \\
\text { muitas vezes, o lote mínimo que o fornecedor pode atender é bastante } \\
\text { grande para as necessidades dos clientes, gerando custos financeiros com } \\
\text { formação de estoque e alto custo de oportunidade dos recursos aplicados, } \\
\text { bem como riscos de perda de produtos e da qualidade destes. }\end{array}$ & 0 \\
\hline \multirow{2}{*}{$\begin{array}{l}\text { Operações de } \\
\text { suprimento }\end{array}$} & $\begin{array}{l}\text { Delivery: esta modalidade implicaria uma comodidade para os gestores à } \\
\text { medida que não precisariam dispender esforços para buscar os materiais e } \\
\text { matérias-primas necessárias. }\end{array}$ & 1 \\
\hline & $\begin{array}{l}\text { FOB: nesta modalidade, os estabelecimentos seriam os responsáveis pelos } \\
\text { suprimentos desde a saída do fornecedor até o local (buscar na casa do } \\
\text { fornecedor) }\end{array}$ & 0 \\
\hline \multirow{2}{*}{ Pedido } & Porta (pré-venda): vendedores visitam estabelecimentos e retiram pedidos & 1 \\
\hline & Telefone: pedidos feitos por telefone & 0 \\
\hline
\end{tabular}

Fonte: Dados da pesquisa

A composição das alternativas possíveis, considerando os atributos e seus níveis, foi delineada segundo o Teorema de Bayes - ou Árvore de Probabilidade - que segundo Meyer (1995), é dada por:

$$
P\left(B_{i} \mid A\right)=\frac{P\left(A \mid B_{i}\right) P\left(B_{i}\right)}{\sum_{j}^{k}=1 P\left(A \mid B_{j}\right) P(B j)} \quad i=1,2, \ldots, k
$$

Diante disso, chegou-se a 32 alternativas possíveis ao entrevistado para realização das Técnicas de Preferência Declarada, que representam o fatorial completo de possibilidades existentes. Porém, as alternativas foram apresentadas em blocos incompletos e balanceados com o intuito de facilitar a análise por parte do entrevistado. 


\begin{tabular}{|c|c|c|c|c|}
\hline PRAZO & FORNECEDORES & LOTE & $\begin{array}{c}\text { OPERACCOES DE } \\
\text { SUPRIMENTOS }\end{array}$ & PEDIDO \\
\hline & & & \\
\hline Até 24 h & Um ou poucos & Pequeno & Delivery & \\
\hline
\end{tabular}

\begin{tabular}{|c|c|c|c|c|}
\hline PRAZO & FORNECEDORES & LOTE & $\begin{array}{c}\text { OPERACOOES DE } \\
\text { SUPRIMENTOS }\end{array}$ & PEDIDO \\
\hline Mais de 24h & Vários & Grande & FOB & Telefone \\
\hline
\end{tabular}

Figura 1 - Ilustração dos atributos utilizados na pesquisa de campo

\subsubsection{Entrevistas}

$\mathrm{Na}$ etapa de execução, o entrevistado deve ser bem esclarecido sobre o procedimento que executará com o conjunto de cartões que lhe é apresentado. Há três medidas de escolha para se obter a informação da preferência do entrevistado: choice, em que o entrevistado escolhe a melhor alternativa; rating, em que o entrevistado atribui notas às alternativas, e ranking, em que o entrevistado ordena as alternativas segundo suas preferências.

Nesse trabalho optou-se pela forma ranking. Segundo relatos de Camargo (2000), o ordenamento é a metodologia menos cansativa para os entrevistados nas condições apresentadas. Nesse método, os blocos de cartões são apresentados separadamente e de forma aleatória e o entrevistado os ordena a partir da alternativa que lhe desperte maior utilidade.

Quanto às entrevistas, recomenda-se que devam ser realizadas através de aplicação in loco com o entrevistado em virtude de serem relativamente demoradas, mas também é possível 
considerar formas mistas em que o material é enviado pelo correio, com a entrevista sendo conduzida por telefone pelo entrevistador (Louviere et al., 2000) ou através da internet. No caso da presente pesquisa, a abordagem ocorreu pessoalmente in loco.

\subsubsection{Análise dos dados}

Para analisar os dados advindos da técnica de Preferência Declarada, foi utilizado o Modelo Logit Multinomial. Admitindo-se que o termo aleatório da função utilidade (1) seja regido por uma distribuição tipo Gumbel, tem-se o modelo Logit Multinomial (Bem-Akiva e Lerman, 1985) que pode ser escrito como:

$$
P_{n}(i)=\frac{e^{\beta_{k} X_{i n k}}}{\sum_{j \in C} e^{\beta_{k} X j n k}}
$$

em que $P_{n}(i)$ é a probabilidade da alternativa $\boldsymbol{i}$ ser escolhida pelo indivíduo $\boldsymbol{n}$ dentro de um conjunto de possibilidades $\boldsymbol{C}$.

\section{Resultados}

Os resultados do modelo estatístico são apresentados na Tabela 2. Observa-se que a ordem de importância dos atributos é: lote, operação de suprimentos, prazo de entrega, quantidade de fornecedores e forma de pedido. Nota-se, ademais, que o atributo lote tem 30,8\% do peso total dos atributos, e o atributo operação de suprimentos tem $24,4 \%$ deste valor. Logo, são dois atributos relevantes na Logística de Suprimento das pousadas junto às fontes de fornecimento.

Em linhas gerais, os resultados sinalizam para as seguintes preferências:

1 Lotes menores são preferíveis aos maiores, pois permitem que os hoteleiros reponham os estoques de acordo com as reais necessidades, não ficando com recursos aplicados em estoque, o que implica comprometimento significativo de capital de giro, com alto custo de oportunidade;

2 Operação de suprimentos, a forma de entrega influi na escolha dos hoteleiros, pois os pedidos entregues na porta eliminam a necessidade de ter logística específica para a busca 
das mercadorias, com economia de custos;

3 O prazo de entrega em até 24 horas é preferível, pois permite que as operações de reposição de mercadorias sejam feitas a medida da necessidade e viabiliza a compra de lotes menores;

4 Um número menor de fornecedores também foi preferível, já que permite um contato mais específico do hoteleiro com o fornecedor e também possibilita a esse que conheça melhor seus clientes, reduzindo custos de transação e viabilizando a formação de confiança, fidelidade e parceria;

5 O sinal negativo no atributo pedido indica que os hoteleiros preferem a forma de utilização de telefones para fazerem seus pedidos ao vendedor atendendo pessoalmente na sua porta. O sinal negativo no atributo pedido indica que os hoteleiros preferem a forma de utilização de telefones para fazer pedidos aos vendedores a atendê-los pessoalmente, o que contraria aos sinais captados na pré-pesquisa.

Tabela 2 - Resultados estatísticos relativos aos atributos

\begin{tabular}{|l|c|c|c|c|}
\hline \multicolumn{1}{|c|}{ Atributo } & Coeficiente & Erro & Teste t & IC.(t=2,5\%) \\
\hline Prazo & 0,4709 & 0,0993 & 4,7410 & {$[0,272 ; 0,670]$} \\
\hline Fornecedor & 0,3192 & 0,0993 & 3,1860 & {$[0,119 ; 0,520]$} \\
\hline Lote & 0,7353 & 0,1022 & 7,1954 & {$[0,531 ; 0,940]$} \\
\hline Operação & 0,6556 & 0,1008 & 6,5027 & {$[0,454 ; 0,857]$} \\
\hline Pedido & $-0,2086$ & 0,0969 & $-2,1532$ & {$[-0,402 ;-0,015]$} \\
\hline
\end{tabular}

Número de Entrevistas $=130 \quad$ Número de Casos $=650$

$\mathrm{F}($ Betas_0 $)=-855,3027 \quad \mathrm{~F}($ Betas_1 $)=-788,5949$

$\operatorname{LR}(-2[\mathrm{~F}(0)-\mathrm{F}(\mathrm{B})])=133,4155$

Fonte: dados da pesquisa. 
O teste $t$ considera a significância dos parâmetros $\beta$, indicando que os resultados obtidos serão significativos se estiverem acima do valor determinado na Tabela $t$ student. O programa LMPC (Souza, 1999) utiliza o teste $t$ com significância de 95\% para estes parâmetros. Considerando que o número de entrevistas é maior do que 120 e os valores do Teste t obtidos são todos, em módulo, maiores do que 1,96, rejeita-se a hipótese de nulidade dos atributos e se aceita que todos contribuem de forma significativa na utilidade (Ortúzar, 2000).

Ressalta-se que os resultados obtidos no Intervalo de Confiança confirmam a aceitação de todos os parâmetros. O Teste da Razão de Verossimilhança, que verifica o valor de LR e compara com o valor tabelado do $c^{2}$, também rejeita a hipótese de nulidade de todos os coeficientes (Brandli e Heineck, 2005).

No entanto, os resultados são diferentes, em termos de ordem dos atributos, quando avaliados de forma separada por região, conforme tabelas 3 e 4. Há inversão de ordem entre os atributos Fornecedor e Pedido entre as preferências declaradas pelas pousadas das regiões de Ouro Preto e Tiradentes. Mais do que isso. Para os estabelecimentos de Tiradentes, o atributo Pedido não contribui significativamente para utilidade, considerando o teste t. Já para os estabelecimentos de Ouro Preto, esse atributo é relevante, mas o atributo Fornecedor não contribui significativamente.

Tabela 3 - Resultados estatísticos relativos aos atributos - Estabelecimentos de Tiradentes

\begin{tabular}{|l|c|c|c|c|}
\hline \multicolumn{1}{|c|}{ Atributo } & Coeficiente & Erro & Teste t & IC.(t=2,5\%) \\
\hline Prazo & 0,5247 & 0,1358 & 3,8636 & {$[0,253 ; 0,796]$} \\
\hline Fornecedor & 0,3980 & 0,1389 & 2,8662 & {$[0,120 ; 0,676]$} \\
\hline Lote & 0,7593 & 0,1390 & 5,4633 & {$[0,481 ; 1,037]$} \\
\hline Operação & 0,5611 & 0,1354 & 4,1443 & {$[0,290 ; 0,832]$} \\
\hline Pedido & $-0,0625$ & 0,1317 & $-0,4749$ & {$[-0,326 ;-0,201]$} \\
\hline
\end{tabular}

Número de Entrevistas $=70$

Número de Casos $=350$

$\mathrm{F}($ Betas_0 $)=-460,5476$

$\mathrm{F}($ Betas_1 $)=-426,1382$

$\mathrm{LR}(-2[\mathrm{~F}(0)-\mathrm{F}(\mathrm{B})])=68,8187$

Fonte: dados da pesquisa 
Tabela 4 - Resultados estatísticos relativos aos atributos - Estabelecimentos de Ouro Preto

\begin{tabular}{|l|c|c|c|c|}
\hline Atributo & Coeficiente & Erro & Teste t & IC.(t=2,5\%) \\
\hline Prazo & 0,4229 & 0,1464 & 2,8890 & {$[0,130 ; 0,716]$} \\
\hline Fornecedor & 0,2351 & 0,1453 & 1,1682 & {$[0,055 ; 0,526]$} \\
\hline Lote & 0,7069 & 0,1514 & 4,6690 & {$[0,404 ; 1,010]$} \\
\hline Operação & 0,7904 & 0,1522 & 5,1940 & {$[0,486 ; 1,095]$} \\
\hline Pedido & $-0,3906$ & 0,1441 & $-2,7097$ & {$[-0,679 ;-0,102]$} \\
\hline
\end{tabular}

Número de Entrevistas $=60 \quad$ Número de Casos $=300$

$F($ Betas_0 $)=-394,7551 \quad F($ Betas_1 $)=-359,2308$

$\operatorname{LR}(-2[\mathrm{~F}(0)-\mathrm{F}(\mathrm{B})])=71,0485$

Fonte: dados da pesquisa

Outra inversão mais significativa refere-se aos atributos melhor ranqueados. Para os estabelecimentos de Ouro Preto, o atributo Operação obteve a preferência dos respondentes, possivelmente refletindo dificuldades de circulação de veículos de entrega das empresas em face às restrições impostas pela Prefeitura local, haja vista a largura e inclinação das ruas e os danos ao patrimônio histórico causados pelo ruído e trepidação dos veículos de entrega. Sendo assim, os estabelecimentos, muitas vezes, podem ser obrigados a ter que ter operação própria para obterem seus suprimentos.

No entanto, para os estabelecimentos de Tiradentes, os suprimentos são obtidos majoritariamente fora do Município. Isto parece criar mais dificuldades para os estabelecimentos, que fazem pedidos de fornecedores de fora, principalmente, São João Del'Rey e Barbacena, que acenam com a necessidade de maiores volumes de compras para viabilizar a entrega, ou mesmo quando tais operações devem ser desenvolvidas pelos próprios estabelecimentos, para viabilizar a viagem.

\subsection{Análise das preferências}

As preferências declaradas pelos agentes responsáveis pelos suprimentos dos 
estabelecimentos de hospedagem da Estrada Real indicaram haver a necessidade de uma logística fortemente orientada pelo critério responsividade. Dado o empreendimento de cunho muitas vezes familiar e de empresários que têm outras atividades profissionais fora das cidades onde mantêm esses negócios, o serviço oferecido pelos fornecedores deve contemplar atendimento flexível e remoto e agilidade nas entregas.

Esta configuração explica também porque os empresários manifestaram certa apreensão da dependência de poucos fornecedores ao abrir mão deste nível do atributo para a segunda opção. Na verdade, tais compras são muitas vezes efetuadas de fora dos estabelecimentos (das residências dos empresários) ou por funcionários. Além do mais, grande parte dos fornecedores não é do local em que o negócio está estabelecido.

Por outro lado, o caráter sazonal da demanda (férias e finais de semana) transmite aos gestores a necessidade de uso de bastante cautela na formação dos lotes de compras. Excessos no volume de compras implicam o comprometimento de volume de recursos financeiros, que têm alto custo de oportunidade, bem como alto risco de perdas, uma vez consideradas as características da demanda e a perecibilidade de boa parte dos produtos. O balanceamento adequado consiste, assim, em antecipações de informações da demanda e estimativa com alta acurácia dos estoques necessários, incluindo a parcela de segurança.

Ou seja, a gestão de estoques pareceu ser a atividade logística declarada mais relevante para os gestores, condicionada pela forma de comprar adotada. Principalmente quando se considera dentre os produtos alvo da investigação aqueles destinados ao cardápio para o café da manhã, lanches e refeições, ou seja, com importante fator de perecibilidade ou perda de qualidade com o tempo.

Boa parte destes requisitos recaem sobre a responsabilidade da atividade de Compras do subsistema Suprimentos. O foco da gestão estratégica de compras envolve a gestão, o desenvolvimento e a integração com a capacidade dos fornecedores, a fim de se obter uma vantagem competitiva, ligada a efeitos de redução de custos e melhorias na qualidade do serviço. 


\subsection{Implicações para a gestão do turismo}

O caminho para uma melhor gestão dos suprimentos poderia ser o uso estratégico da função de compras e o desenvolvimento de parcerias com fornecedores. Parcerias são, segundo Lambert et al (1998), um relacionamento de negócios personalizado, com base na confiança mútua, no relacionamento aberto e no compartilhamento de riscos e de ganhos. Confiança, na opinião de Chopra e Meindl (2003), envolve a crença de que cada estágio está interessado no bem estar dos outros e não tomaria medidas sem considerar seu impacto nesses outros estágios. Para Monczka et al (2002), refere-se à crença na reputação, na competência, na força ou na sinceridade do parceiro de negócios.

Desta forma, os ganhos desejados poderiam acontecer em suprimentos mais freqüentes e em pequenos lotes, com frete por conta do fornecedor. Pela ótica do fornecedor, esta flexibilidade é viável desde que possa se planejar para ofertar os itens necessários com certa garantia de regularidade das transações.

No caso dos estabelecimentos da Estrada Real, o principal atributo declarado, os lotes de compras, que implicam formação de estoques, poderiam ser estrategicamente tratados via fornecedores. A seleção de fornecedores por parte das pousadas, oferecendo como contrapartida projeções de compras regulares, poderia ser o caminho para se atingir resultados significativos em termos de logística, implicando mais facilidades de obtenção de materiais e suprimentos alimentícios de uso menos freqüente, num prazo razoável, bem como nas demais condições estabelecidas.

O processo de seleção dos fornecedores poderia ocorrer por negociação, que poderia até mesmo ser usada pelo conjunto de estabelecimentos de uma mesma região, ao menos para produtos mais gerais como os de limpeza a alguns do gênero alimentício de base. Assim, poucos fornecedores poderiam atender uma região inteira, o que aumenta a quantia fornecida, gerando economias de escala sem ter que exigir lotes mínimos. Além disso, atendendo a um número maior de estabelecimentos, os fornecedores poderiam fazer entregar mais freqüentes, mesmo que sejam fornecedores de fora da cidade, pois a quantidade comprada e a freqüência dos pedidos, considerando o grupo inteiro de clientes, permitiriam tal procedimento com melhor aproveitamento de um roteiro de distribuição. 


\section{Conclusões}

O objetivo geral da presente pesquisa foi identificar necessidades e expectativas dos prestadores de serviço relacionados às pousadas de Ouro Preto e Tiradentes na Estrada Real (MG), em termos de estratégia desejável da logística de suprimentos. No caso dos serviços relacionados de hospedagem de pequeno porte, o uso estratégico da logística permite alcançar diferenciais competitivos tanto no aspecto custos quanto na qualidade do atendimento.

Através de pesquisa empírica, de caráter exploratório, foi feito levantamento de dados em campo por aplicação de cartões de preferência declarada aos empresários e gerentes dos estabelecimentos de pousadas nas regiões de Ouro Preto e Tiradentes, trechos dos mais consolidados em turismo da Estrada Real. Os atributos investigados foram: Prazo de atendimento, Número de fornecedores, Lote, Operações de suprimentos e Forma de pedido.

Os resultados indicaram que o cenário de suprimento preferido pelos respondentes pode ser caracterizado como: os suprimentos devem ser realizados com responsividade, em até 24 horas, por um ou poucos fornecedores, em lotes pequenos, que são entregues nos estabelecimentos pelos fornecedores tendo os pedidos sido feitos por telefone, sendo esta a exata ordem de importância dada ao conjunto dos atributos do mais para o menos importante deles.

Além disso, a troca compensatória que eles estariam dispostos a fazer seria a de abrir mão de poucos fornecedores, mas mantendo os demais atributos conforme apresentados acima. Essas foram as duas situações hipotéticas mais aceitáveis e desejáveis pelos entrevistados, dentre as oferecidas no estudo.

Entretanto, considerando a realidade vivida por eles, que inclui dificuldade de acesso para distribuição por parte dos fornecedores (sobretudo em Ouro Preto devido às restrições de caminhões de grande porte no centro da cidade, onde está localizada a maior parte das pousadas), escassez de fornecedores locais qualificados, grande distância dos grandes centros urbanos utilizados atualmente pelos compradores, que são Belo Horizonte, Rio de Janeiro e São Paulo, tais práticas não são totalmente viáveis.

Sendo assim, conclui-se que uma estratégia de forte impacto para esta atividade econômica 
das regiões pesquisadas deveria contemplar política de redução da base de fornecedores. Tal estratégia deveria ser baseada na atividade compras. A negociação com poucos fornecedores, conforme explanado nas seções anteriores, pode trazer vantagens competitivas tanto aos clientes quanto aos fornecedores, o que será percebido pelos turistas no que diz respeito a maior satisfação com serviços e os cardápios dos estabelecimentos das regiões.

Além disso, essa estratégia influencia o desempenho de todos os outros atributos desejados. Isso é possível, pois, negociando-se com poucos fornecedores, os clientes se tornam fiéis a eles e estes, por sua vez, respondem com: melhor qualidade; maior responsividade, podendo entregar a compra em menor tempo e com maior freqüência; menor custo, pela garantia e segurança de uma relação de longo-prazo; e maior conhecimento das preferências dos clientes, permitindo pedidos por telefone sem que haja dúvidas ou erros.

Ademais, se adotada de forma conjunta, a estratégia de compra pode trazer resultados ainda mais significativos para os estabelecimentos, que juntos poderiam se tornar ainda mais competitivos e prontos para oferecer um serviço de melhor qualidade aos turistas da Estrada Real. Dessa forma, pode-se concluir também que a formação de um pool de compras ou uma parceria entre os meios de hospedagem seria o desejável para que as sugestões anteriores pudessem ser alcançadas.

\section{Referências}

ALMEIDA, L. M. W.; GONÇALVES, M. B. 2001. "A methodology to incorporate behavioral aspects in trip-distribution models with an application to estimate student flow". Environment and Planning A, v. 33 , p. $1125-1138$.

BATEMAN, I. 2002. Economic valuation with stated preference techniques: a manual. Departament for Transport. Edward Elgar.

BEN-AKIVA, M.; LERMAN, S.R. 1985. Discret Choice Analysis: Teory and Aplication to Travel Demand. London: The Mit Press.

BRANDLI, L.L.; HEINECK, L.F.M. 2005. "As abordagens dos modelos de preferência declarada e revelada no processo de escolha habitacional”. Ambiente Construido, Porto Alegre, v. 5, n. 2, p. 61-75, abr./jun.

BYRNS, R. T. 1996. Microeconomia. São Paulo: Makron Books. 
CAMARGO, O. Identificação dos principais atributos considerados no transporte de cargas: estudo de caso no oeste paranaense. Tese de doutorado não-publicada, Pós-Graduação em Engenharia de Produção. Universidade Federal de Santa Catarina, Florianópolis, Brasil, 2000.

CHING, Y. H. 2001. Gestão de estoques na cadeia logística integrada. 2. Ed. São Paulo: Atlas, 194 p.

CHOPRA, S.; MEINDL, P. 2003. Gerenciamento da cadeia de suprimentos: estratégia, planejamento e operação. São Paulo: Prentice Hall.

CHRISTOPHER, M. 2007. Logística e gerenciamento da cadeia de suprimentos: Criando redes que agregam valor. São Paulo: Thomson.

COSTA, A. G.; RENGER, F. E.; et al. 2002. Cartografia das Minas Gerais: da Capitania à Província. Belo Horizonte: Editora UFMG.

ELLRAM, L. 1992. Partners in international alliances. Journal of Business Logistics, v. 13, p. 1-25.

HANSEN, K. V.; JENSEN, Ø.; GUSTAFSSON, I.-B. 2005. The meal experience of a' la carte restaurant customers, Scandinavian Journal of Hospitality and Tourism, 5: 135-151.

HOYT, J.; HUQ, F. 2000. From arm's-length to collaborative relationships in the supply chain. International Journal of Physical Distribution \& Logistics Management. v. 30, n. 9, p. 750.

INSTITUTO ESTRADA REAL/FEDERAÇÃO DAS INDÚSTRIAS DE MINAS GERAIS (FIEMG). 2004. Guia Fiat Doblò Adventure Estrada Real. Belo Horizonte: Editora Abril.

JONES, P. An overview of Stated Preference Techniques. 1991. PTRC Course: Introduction to Stated Preference Techniques. [s. 1. s. n.].

KOTLER, P., BOWEN, J.; MAKENS, J. 1999. Marketing for Hospitality and Tourism. $2^{\text {nd }}$ ed. Essex: Prentice Hall.

KROES, E. P.; SHELDON, R. J. Stated Preference Methods. 1988. Journal of Transport Economics Policy, v.22, n.1, p.11-20.

LAMBERT, D. M.; COOPER, M.C; PAGH, J. D. 1998. Supply chain management: implementation issues and research opportunities. International Journal of Logistics Management. v. 9, n. 2, p. 1-19.

LEÃO, F. 1999. De volta a Estrada Real. Belo Horizonte: Rona Editora.

LOUVIERE, J.J.; HENSHER, D.A.; SWAIT, J. D. 2000. Stated Choice Methods: analysis and application. 1a ed. Cambridge: Cambridge University Press.

MALHOTRA, N. 2001. Pesquisa de marketing: uma orientação aplicada. Porto Alegre, Bookman.

MEYER, P. L. 1995. Probabilidade: aplicações à estatística. Rio de Janeiro: Livros Técnicos e Científicos Editora-LTC.

MONCZKA, R.; TRENT, R.; HANDFIELD, R. 2002. Purchasing and Supply Chain Management. ${ }^{\text {nd }}$ edition. Cincinnati: Thomson Learning, $760 \mathrm{p}$. 
MOSSBERG, Lena. 2007. A Marketing Approach to the Tourist Experience. Scandinavian Journal of Hospitality and Tourism, 7 (1): 59-74.

ORTÚZAR, J. D. 1998. Modelos de demanda de transporte. 2.ed. Santiago: Ediciones Universidad Católica de Chile.

de Chile. 249 p.

2000. Modelos econométricos de elección discreta. Chile: Ediciones Universidad Católica

POIRIER, C. C.; REITER, S. E. 1997. Otimizando sua rede de negócios: como desenvolver uma poderosa rede entre fornecedores, fabricantes, distribuidores e varejistas. São Paulo: Futura.

QUAN, S.; WANG, N. 2004. Towards a structural model of the tourist experience: An illustration from food experiences in tourism, Tourism Management, 25: 297-305.

SOUZA, O. A. de. 1999. Delineamento experimental em ensaios fatoriais utilizados em preferência declarada. Tese de Doutorado - Engenharia de Produção/Universidade Federal de Santa Catarina. Florianópolis.

Recebido em: 29/06/2009

Aprovado em: 01/02/2010 (1 ${ }^{\mathrm{a}}$ versão) $20 / 05 / 2010$ ( $2^{\circ}$ versão) 